\title{
Differentiation of Roles: Instructional Designers and Faculty in the Creation of Online Courses
}

\author{
Colleen Halupa ${ }^{1}$ \\ ${ }^{1}$ Online Education, East Texas Baptist University, Marshall, TX \\ Correspondence: Colleen Halupa, Dean Online Education, East Texas Baptist University, Marshall, TX, USA Tel: \\ 1-903-923-2038. E-mail: chalupa@etbu.edu
}

Received: November 10, 2018

Accepted: December 21, 2018

Online Published: January 15, 2019

doi:10.5430/ijhe.v8n1p55

URL: https://doi.org/10.5430/ijhe.v8n1p55

\begin{abstract}
Instructional design has continued to change and undergo metamorphosis. A key component of this process in higher education is the collaboration between an instructional designer and one or more faculty members to create a robust, quality online course. In this collaborative process, instructional designers are clearly the design expert, while the faculty member is the content expert. However, problems occur when roles are not clearly delineated. Conflict is often reported by instructional designers who feel they are not respected by faculty. Conflict can also occur when instructional designers cross the line and try to influence content instead of providing guidance on content delivery. In order to decrease conflict, the roles of instructional designers and the faculty they collaborate with must be clearly defined. Both the instructional designer and the faculty member should clearly articulate their expected roles in the collaborative course creation process. In addition, written policies and procedures for the instructional design process are crucial to the success of these collaborative relationships.
\end{abstract}

Keywords: faculty resistance, instructor designer roles, subject matter expert roles

\section{Introduction}

\subsection{Introduction}

Metamorphosis has continued in the field of instructional design since its inception in military training during World War II. The field was initially championed by psychologists and in the 1950's became the purview of educators, although educators such as Ralph Tyler made a significant contribution to the field with the creation of behavioral objectives back in the 1930s. Benjamin Bloom, in the 1950's, created the quintessential taxonomy that revolutionized instructional design. His work was further built upon and improved by Robert Gagne, an educational psychologist, and Loren Anderson and colleagues (Reiser, 2001).

Although instructional design theory, including instructional systems design, continued to be used in technical training and other military training since the mid-twentieth century, it was not widely used in higher education in face-to-face classroom instruction. It gained popularity outside of the military and industry in the late twentieth century when online learning became possible and widely offered by universities throughout the United States. Many faculty have not been exposed to instructional design practices and theories; therefore, collaborating with an instructional designer (ID) in the creation of an online course can be a daunting prospect. They may be unused to the structure and the detailed information they may be required to provide such as implicit directions for assessments, as well as grading rubrics. Faculty may fear a loss of control over the courses they create and teach in the instructional design process. Instructional designers have to be careful to facilitate the design and delivery of course information without crossing the boundaries of acting like or superseding the faculty member who is a subject matter expert.

\subsection{Importance of the Problem}

More information is needed on the delineation of the roles of instructional designers and faculty who serve as subject matter experts to ensure difficulties do not occur in the online course creation process (Intentional Futures, 2016). There is a paucity of literature on this topic. Best practices need to be established because this is a point of confusion (Castro-Figueroa, 2009; McGuire, 2016) and potential conflict. When roles are clearly delineated, both faculty and IDs know how to proceed, as well the role each fulfills in the collaborative process. 


\section{Brief History of Instructional Design}

Educators and psychologists began advocating for the use of educational objectives as early as the 1900s. However, the use of objectives by educators did not become popular until the 1930s due to the work of Ralph Tyler, the first educator to really adapt this practice into practical use. The field of instructional design began during World War II when educators and psychologists were called upon to develop military training to assist in the war effort. This combination of educators and psychologists helped to create the beginnings of instructional design by crafting objectives that focused on human behavior and learning, as well as effective testing methods to determine what people were most appropriate for specific jobs. After World War II, the psychologists and educators involved in this initiative continued to research these practices concentrating on analysis, design and evaluation of instruction. B.F. Skinner then contributed to this movement by developing programmed instruction to solve educational problems (Reiser, 2001).

In the 1950s Benjamin Bloom created his taxonomy for the measurement of action or learning in educational objectives. In the early 1960's Robert Mager wrote the first textbook on how to write objectives for educators and criterion-referenced testing also became popular. Reiser (2001) noted this criterion-referenced testing expanded the idea of basic instructional design principles since it could be used to measure student knowledge before and after education occurred. It was also discovered during this time that the plethora of materials developed during the 1950s in math and science fields was ineffective. All of these concepts were linked together in the mid-late 1960s to create the field of instructional design, a term which was coined by Gagne (Reiser, 2001).

During the 1970s the number of instructional design models grew significantly. Going back to its roots in World War II, many branches of the U.S. military adopted instructional design models. Business and industry incorporated instructional design principles to maximize the effectiveness of their employee training. However, instructional design was rarely used in higher education.

Chao, Saj and Hamilton (2010) noted instructional designers were rarely found on college campuses until the 1990s when internet technology advanced and online learning became prevalent. However, the traditional instructional design models, such as ADDIE, did not work as well in academia, so instructional designers had to hone their practice to meet higher education needs.

In 1998 Guernsey in the Chronicle of Higher Education declared the new profession of instructional designer, that combined instructional technology and teaching, was born due to the movement of courses online. This position's role was to help faculty conceptualize how best to teach content online. However, some universities had created instructional designer positions even before 1998 (Pan \& Thompson, 2009). Since that time, the use of instructional designers has continued to grow in higher education primarily in online education, but also in face-to-face teaching as universities began to develop teaching and learning centers in the early $21^{\text {st }}$ century.

\section{Roles in Creating Online Courses}

Puzziferro and Shelton (2008) said, "no one person is capable of discharging all of the expertise levels and roles inherent" in the creation of an online course (p. 119). Collaborative models for online curriculum development have been widely discussed in the literature (Chao et al., 2010; Diamond, 2011; Moallem, 2003; Reeves, Herrington \& Oliver, 2004; Vooggt et al., 2015; Xu \& Morris, 2007). The roles of instructional designer and faculty members who served as content experts and writers on online courses will be discussed in the following sections.

\subsection{Instructional Designer Roles}

Instructional designers are usually not subject matter experts in the disciplines in which they design courses since designers usually assist with courses in multiple disciplines. For this reason, they should not make suggestions or decisions about content since they do not have the education or experience in the areas where they assist in design. Some instructional designers do have advanced education and may meet credentialing requirements for a course they may be tasked with designing. However, even if an instructional designer is a subject matter expert, he/she should not cross the line of acting like a subject matter expert in lieu of the faculty member that is assigned to create the course and who has expertise in the area. In other words, faculty should determine the content that is to be provided to the students and instructional designers help faculty to decide on the best way to present it.

Connie Malamed, an instructional designer for over 20 years created a list that outlines the qualities of an ideal instructional designer. They are:

- Intuitively and conceptually understand how people learn

- Know how to connect with students (the audience) to get them to engage with content 
- Be able to look at the course with a student's eyes to determine problems and issues

- Understand innovative and creative instructional strategies

- Knows how to use instructional technology

- Work collaboratively with faculty subject matter experts

- Write effective copy and instructions

- Be able to visualize the final educational product (2009).

Bichelmeyer, Misanchuk and Malopinsky (2001) reported the following roles for instructional designers:

- Team development

- Appropriateness of technology

- Establish minimum technology standards

- Provide technology training

- Develop intellectual property policies

Kenny, Zhang, Schweir and Campbell (2005) performed a meta-analysis on current articles that addressed instructional designer roles. They reported the research of Cox and Osguthorpe (2003) who surveyed 142 instructional designers to determine their roles. The respondents reported $47 \%$ of the time they performed instructional design tasks with the remaining 53\% spent on organizational tasks such as project management and meetings. They estimated on average, course development took $29 \%$ of their time. In addition, Kenny et al. noted Roberts, Jackson, Osborne, and Somers Vine (1994) reported the following roles for instructional designers in Tasmania:

- Act as a surrogate student

- Pedagogical advisor

- "Critical eye" that addressed "balance...consistency.... sequence (p. 7)

- Media advice

- Assessment advisor

- Proofreader (Kenny et al., 2005)

Overall, Kenny et al. (2005) noted the following common roles for instructional designers from the 1990s through the early 2000's:

- Communication

- Proofreading and editing

- Media development

- Graphic design

- Project management

- Team building

- Technology training (faculty and students)

According to Tantivat and Allen (2006), the following are roles of an instructional designer in the creation of online courses:

- Experience designing courses in various field; techniques applied in various fields can be utilized in other fields

- Understanding of the needs of online learners

- A student surrogate: sees the course through the eyes of the student

- Design skills

Puzziferro and Shelton (2008) defined the following roles for an instructional designer in a two-member team (faculty course developer and instructional designer) where a second faculty member with expertise in the subject provides the review: 
- Employs and instructional design model for the creation of the course (i.e. ADDIE)

- Provides course design and online pedagogy assistance

- Acts as the project manager to keep the project on track

- Ensures course design is adhering to quality practices in online learning

- Assists the faculty member in selecting learning objects to support online pedagogy

- Provide "static resources" such as links to tutoring, technology assistance, accessibility, etc.

Miller and Stein (2016) reported the results of the roles identified by a group of instructional designers at New Jersey universities in the summer of 2015. These roles included:

- Technology and online pedagogy training

- Moving courses from one learning management system to another

- Creating online courses with faculty subject matter experts

- Producing video and other multimedia

- Learning management system and instructional technology support

- Training faculty to teach more effectively using technology

- Supporting student using learning management systems

- Ensuring courses meet accessibility standards

- Assist faculty in creating online assessments to minimize cheating

In 2012 the International Board of Standards for Training (IBSTPI), Performance and Instruction revised the competencies for instructional designers. These competencies are indications of behavior (Richey, Fields \& Foxon, 2001). IBSTPI acknowledged instructional designers do come into the field with varying educational and technological backgrounds. In addition, they work in numerous types of organizations to include K-12 education, business, and higher education. However, these competencies are what is required to perform successfully in the fields. These are broken down into essential, advanced and managerial expertise. The 2012 IBSTPI standards are displayed in Tables 1-3 below.

Table 1. IBSTPI Essential Standards for Instructional Designers

\begin{tabular}{ll}
\hline Number & Competency \\
\hline 1 & Communicate effectively in visual oral, and written form. \\
3 & $\begin{array}{l}\text { Update and improve knowledge, skills, and attitudes pertaining to the instructional design } \\
\text { process and related fields. }\end{array}$ \\
5 & Identify and respond to ethical, legal, and political implications of design in the workplace. \\
7 & Identify and describe target population and environmental characteristics. \\
8 & Select and use analysis techniques for determining instructional content. \\
9 & Analyze the characteristics of existing and emerging technologies and their potential use. \\
10 & Use an instructional design and development process appropriate for a given project. \\
11 & Organize instructional programs and/or products to be designed, developed, and evaluated. \\
12 & Design instructional interventions. \\
14 & Select or modify existing instructional materials. \\
15 & Develop instructional materials. \\
18 & Revise instructional and non-instructional solutions based on data. \\
\hline
\end{tabular}


Table 2. IBSTPI Advanced Standards for Instructional Designers

\begin{tabular}{ll}
\hline Number & Competency \\
\hline 2 & Apply research and theory to the discipline of instructional design. \\
4 & Apply data collection and analysis skills in instructional design projects. \\
6 & Conduct a needs assessment in order to recommend appropriate design solutions and strategies. \\
13 & Plan non-instructional interventions. \\
16 & Design learning assessment. \\
17 & Evaluate instructional and non-instructional interventions. \\
19 & Implement, disseminate, and diffuse instructional and non-instructional interventions. \\
22 & Plan and manage instructional design projects.
\end{tabular}

Table 3. IBSTPI Managerial Standards for Instructional Designers

\begin{tabular}{ll}
\hline Number & Competency \\
\hline 20 & Apply business skills to managing the instructional design function. \\
21 & Manage partnerships and collaborative relationships.
\end{tabular}

These competencies are also grouped functionally: a) professional foundations (standards 1-5), b) planning and analysis (standards 6-9), c) design and development (standards 10-16), d) evaluation and implementation (standards 17-19), and e) management (standards 20-22). Each of these specific standards have performance statements that should be met to attain competency in the standard. Even if the competency is an essential one, there may be some performance statements at the advanced or managerial level.

Campbell, Scheier and Kenny (2009), and Tracey, Hutchinson and Gryzbyk (2014) noted an additional role of an instructional designer is that of a change agent. They note they are agents of change because they work directly with faculty and help shape institutional change in pedagogy and teaching. This is particularly true in the online environment. Campbell et al. noted community building is a key role for instructional designers. Respect and common courtesy can go a long way to developing a productive, collegial relationship with faculty.

Campbell et al. (2009) also identified instructional designers as instructional advisors. The word "advisor" is the key to a successful working relationship with faculty. Chao et al. (2010) noted two key roles of instructional designers are to act as advisors to faculty on the issue of course quality. They also play a significant role in educating faculty how to use instructional technologies. An instructional "dictator" is likely to be perceived negatively by faculty. Instructional dictators often cross the line into dictating content rather than design. This is a key error instructional designers can make because it leads to conflict and prolongs course creation.

Tracey et al. (2014) defined an additional role of instructional designers as, "dynamic drivers" who "recursively refine both problem and solution until an innovative outcome is reached" (p.3). They noted instructional designer roles are very process-driven, yet subjective, based on the designers own education, knowledge and experience base.

Pan and Thomas (2009) noted one of the participants in their research study said the following:

I think that is how all the instructional designers need to conduct themselves... to be perceived as...they should be very warm, very interpersonal, very personable, very highly communicative using whatever resources and personalities are there to have an engaging, warm, and robust relationship...faculty would feel a lot of support being there together with each other (p. 39).

Participants in this study also reported instructional designers should be warm and amiable.

The University of Regina, a public research university in Canada, lists the following roles for instructional designers:

- Keep abreast of best practices in teaching and learning

- Awareness of emerging technologies

- Assist instructors in developing meaningful instruction; recommend instructional strategies

- Provide guidance on accessibility and copyright 
- Train new faculty in instructional technology

- Manage curriculum projects

- Suggest how to make course elements work effectively

- Assess learning objectives

- Create graphics/multimedia (2016)

Intentional Futures (2016) estimated there were13,000 instructional designers in the U.S. They surveyed 863 instructional designers who identified the most common duties they perform:

- Design courses, particularly for online delivery

- Manage the efforts of faculty to increase student learning

- Train faculty to leverage instructional technology and online pedagogies

- Provide faculty support

Only $20 \%$ of instructional designers reported creating or revising courses in a learning management system daily. Sixty percent of the respondents trained a faculty member in technology at least once a day and $73 \%$ reported managing projects every day (Intentional Futures, 2016). Starting in the latter part of the first decade of the $21^{\text {st }}$ century, a significant instructional design role has been to implement quality standards such as Quality Matters. Although faculty roles are different, there are some gray areas in instructional designer and faculty roles.

\subsection{Faculty Roles}

Puzziferro and Shelton (2008) defined the following roles for a faculty member in a two-member team member (faculty course developer and instructional designer) where a second faculty member with expertise in the subject provides the review:

- Selects and designs course materials

- Ensures academic rigor exists

- Subject matter expert; determines content to be included

- Create course learning objectives/goals

- Determine mastery activities

- Create authentic assessments

Additional duties may include the following:

- Create assessments that match the level of course objectives

- Creates supplementary documents, videos, podcasts, etc. to enhance student learning of content

- Creates curriculum map to link course objectives to program or general education outcomes

- Ensures all content needed by the student to succeed in the field or to successfully master future material in the topic area is covered.

In 2003, IBSTPI also published instructor standards for the creation of education and instruction. These standards are outlined in Table 4 below. There are 17 standards in five separate categories. 
Table 4. IBSTPI Instructor Standards

\begin{tabular}{lll}
\hline Category & Number & Competency \\
\hline Professional Foundations & 1 & $\begin{array}{l}\text { Communicate effectively. } \\
\text { Update and improve one's professional } \\
\text { knowledge and skills. } \\
\text { Comply with established ethical and } \\
\text { legal standards. } \\
\text { Establish and maintain professional } \\
\text { credibility. }\end{array}$ \\
& 3 & \multicolumn{1}{c}{ instructional methods } \\
Planning and Preparation & 5 & $\begin{array}{l}\text { Plan } \\
\text { materials. }\end{array}$ \\
& 4 & Prepare for instruction.
\end{tabular}

\section{Instructional Methods and 7} Strategies

8

9

10

11

12

13
Stimulate and sustain learner motivation and engagement.

Demonstrate effective presentation skills.

Demonstrate effective facilitation skills.

Demonstrate effective questioning skills.

Provide clarification and feedback.

Promote retention of knowledge and skills.

Promote transfer of knowledge and skills.

\begin{tabular}{|c|c|c|}
\hline \multirow[t]{2}{*}{ Assessment and Evaluation } & 14 & Assess learning and performance \\
\hline & 15 & Evaluate instructional effectiveness. \\
\hline \multirow[t]{2}{*}{ Management } & 16 & $\begin{array}{l}\text { Manage an environment that fosters } \\
\text { learning and performance. }\end{array}$ \\
\hline & 17 & $\begin{array}{l}\text { Manage the instructional process } \\
\text { through the appropriate use of } \\
\text { technology }\end{array}$ \\
\hline
\end{tabular}

In the creation of online instruction, the roles and specializations of instructional designers and faculty are very different. In addition, some additional authors weighed in on faculty roles when working with an instructional designer to create courses and content.

Tantivivat and Allen (2006), instructional designers in Wisconsin at the time of publication, note the following roles faculty hold in developing online instruction with an instructional designer.

- In-depth subject matter expertise obtained by advanced education and/or experience

- Relevance of content and knowledge of what should/should not be covered

- Expertise in teaching the topic previously

- Knowledge of appropriate pedagogies for teaching the subject

$\mathrm{Xu}$ and Morris (2007) note faculty are responsible for "content, pedagogy and preparation of the content to meet design" (p. 37). Costley and Lange (2016) found the more instructional control a faculty member has in an online 
course, the more positive the learning outcomes were viewed by students. Smaldino and Yamagata-Lynch (2015) discussed design issues with online "courses in a box" (p. 71) which are created with minimum faculty intervention which are used by many universities. These courses are often taught by adjuncts and are primarily instructional design rather than faculty driven. They noted when other instructors taught these types of courses, they often had difficulty maximizing the effectiveness of their instruction. This is another reason collaboration is so important in the creation of online courses.

The University of Regina, a public research university in Canada lists the following roles for faculty who write online and hybrid courses:

- Meet all project deadlines

- Consider and incorporate feedback from instructional designers

- Provide bibliographic information for all resources

- Work with the course development instructional design team (2016).

If both faculty and instructional designers know and understand each other's roles, this can ensure the collaboration process is more effective and efficient.

\section{The Collaborative Process}

$\mathrm{Xu}$ and Morris (2007) note, "Developing a course for online instruction requires content knowledge and understanding of the interactivity, technological requirements, and possibilities in the asynchronous environment" ( $p$. 35). Similar to the old adage two heads are better than one, two differing perspectives on online course development can prove to be very valuable. Online pedagogies and methods are different than those in the face-to-face classroom. In addition, delivery in the online environment requires the use of robust technologies; new technologies are available to use in education all the time. With the pressures of teaching, course creation, advising, research, and publication already on the faculty members' shoulders, it is not possible or probable that many faculty members will become experts on online pedagogies unless their specific discipline is instructional design or higher education. The role of the instructional designer is to assist faculty in creating courses based on the most current design principles in online learning. $\mathrm{Xu}$ and Morris note while faculty experts have the knowledge of what to teach, instructional designers can assist in how to organize it to enhance student learning.

Many faculty, particularly those at traditional universities that have numerous online offerings or a separate online "arm" of the university, may not be familiar with creating online courses in a collaborative manner. For centuries, faculty members have designed their own instruction and assessments by themselves or sometimes in collaboration with other faculty. Researchers (Carnevale, 2000; Fredericksen, Pickett, Shea, Pelz, \& Swan, 2000; Luck, 2001;). Xu \& Morris (2007) have noted instructional designer relationships with faculty can be challenging and is often a "delicate and negotiated role" (2007, p. 36).

$\mathrm{Xu}$ and Morris (2007) note it is critical to prevent barriers to communication and suggest the best way to do this is to specifically delineate the roles and responsibilities of the faculty member and instructional designer in the creation of online content. They note each should be aware of the other team member's roles and responsibilities in order to prevent conflict and communication breakdown. They note the designation of responsibilities must be explicit; this will prevent faculty from feeling instructional designers are overstepping the boundaries of course design and trying to act as subject matter or content experts. Consequently, faculty members must understand the assistance that can be provided to them by the instructional designer. It is important that both the designer and the faculty member have respect for each other's skill set and expertise. Shared values are also important. When done properly, faculty can view this collaborative process as a valuable process that increases the quality of instruction. When responsibilities and roles are not specifically outlined, communication can break down and conflict can result. Even breakdowns in communication that do not go as far as true conflict can negatively impact the process. For instance, if faculty members do not honor course deadlines, this can result in poor quality content or the cancellation of a course. If instructional designers make the process too time consuming, difficult, are overly prescriptive, or lack flexibility, this can result in faculty no longer wishing to create online courses. Although faculty often get paid additional money for the creation of online courses, or do it as part of a teaching load, if the process is too cumbersome, faculty may feel it is not worth the compensation received. This can result in the use of numerous adjunct faculty who do not have as much of a stake in the university, and are not as aware of the university program specifics, policies and procedures. The key is for each member to stay true to their specified role and not overstep these boundaries unless specifically requested for feedback by the other member on the tasks to be performed. 
It is important to note both instructional designers and faculty members have very different levels of expertise in regards to the creation of online learning. Although most instructional designers have an overall skill level, some instructional designers are experts in instructional design theory and the use of prepackaged instructional technologies. Others may not be as well versed in design theory, but are experts in web design, html and other more technical aspects of instructional design. It is helpful if faculty members are aware of the designer's specific expertise. In addition, instructional designers need to know in when to bring in additional technical expertise for design tasks. Some instructional designers report a lack of respect for their expertise from some faculty (Miller \& Stein, 2016).

Consequently, faculty members also may have very different levels of expertise regarding online instruction. Some faculty may be novices with little or no online experience in creating online courses. Other faculty members may have written or created dozens of online courses. Instructional designers must adjust and adapt to the various levels of expertise and experience. If a designer treats a novice faculty member as an experienced one, there are likely to be issues. Consequently, if a designer treats an experienced faculty member as if he/she does not know anything about online course development, this can cause resentment. In general, instructional designers are patient with novice faculty members and grateful for those faculty members who do not need as much assistance and are more independent in their creation of a course.

Although two-member online course creation teams are fairly common, in many instances after the course is created it needs to go through an outside reviewer or curriculum committee for peer review. This can result in additional changes. One way to reduce the number of changes that may be required after the course is essentially completed is to use a collaborative online course design team that consists of an instructional designer and two or more faculty members. Adding additional faculty members to the course creation team allows varying perspectives from two different subject matter experts, and it increases the chance that all crucial content will be included. Xu and Morris (2007) researched the dynamics of a curriculum group tasked to design online higher education instruction for a large public university. This university had four different campuses within the system; four faculty members (one from each campus) were included in the group, as well as a technical support staff member, and an instructional designer who acted as the project manager. Two of the faculty members had extensive experience in online instruction and course creation, while two did not. Throughout the collaborative process there were four team meetings and asynchronous discussion took place on a discussion board. The researchers observed the planning meetings, conducted interviews with the participants and analyzed the asynchronous communication.

The instructional designer who acted as the project manager served primarily as a central point that kept the group on track. She assisted in the resolution of conflict within the group and ensured there was consistent, frequent communication with the group. She ensured the group adhered to policy and quality standards,, and she clearly noted she was not "overseeing" (Xu \& Morris, 2007, p. 41) or in charge of the group. If these perceptions had existed, her role would not have been as effective and collaboration within the group could have disintegrated. She went on to note, "I am not going to change content...I am not a content expert...I am going to change things to...increase interaction... and enable students to better understand the material" (p. 41). Xu and Morris (2007) noted faculty made the instructional content decisions, while the instructional designer enhanced student collaboration and interactivity since this was not as great of a concern to the faculty members, particularly the novice ones.

This process was viewed favorably by all team members even though faculty members initially had to meet more than once to collectively agree on content; although they were all discipline experts, they had different experiences and opinions. However, the faculty members did experience an increased workload and viewed this process as much more time-intensive. Even in a team environment, there was conflict between the faculty members and the instructional designer because they were approaching the course from two different perspectives. Faculty felt this somewhat impacted their autonomy in regards to the course. However, all faculty reported this was a very beneficial faculty development opportunity (Xu \& Morris, 2007).

Miller and Stein (2016) noted faculty buy-in with the instructional design process is more likely to occur if the instructional designers report to the academic governance rather than the information technology/financial division of the university. This ensures faculty and instructional designers have similar governance in regards to academic policies and procedures. They also note faculty tend to balk at top down initiatives (such as the Dean or Provost demanding compliance with instructional design policies); however, it is important that leadership support of instructional design practices is supported by higher level administration. 


\section{Conflict and Resistance in the Development Process}

As early as 1989, prior to the advent of online learning, John Wedman wrote about resistance to instructional design processes. He noted course writers may resist instructional design processes because they view them to be too time intensive and because they delay course development. This may result in course writers who do not follow an instructional design process or model who then develop materials without first determining course objectives to outline what students need to know. In traditional face-to-face courses, in the past faculty often created syllabi that did not even include student-centered course objectives. In addition, many faculty created courses based on a textbook rather than what students actually need to know. Wedman (1989) noted this resistance most often came from faculty who were subject matter experts, but who had little training in pedagogy or curriculum practices. This resistance often leads to conflict with the instructional designer assigned to the faculty member who is developing an online course. Intentional Futures (2016) reported the number one obstacle instructional designers face is lack of faculty buy-in. The $10^{\text {th }}$ largest obstacle was working with faculty.

Wedman (1989) also noted instructional designers can cause conflict and damage the working relationship with faculty by pushing their own agendas and insisting on delays that may not be reasonable. The following is an actual real-life example of how this can occur. Professor A was given a course release in the fall semester to create an online course by his dean. The instructional designer assigned to him was working with other faculty and did not have this course scheduled for creation until the spring. If the instructional designer pushes to delay the creation until spring, the professor will not have time to do it adequately. The instructional designer is too busy to fully devote her time in the fall semester to Professor A. There are different potential solutions to issues such as this scenario that can prevent conflict. For instance, if there is extensive written guidance that explicitly outlines what the Professor A needs to do, then he and the instructional designer can have a brief meeting to go over the material and then Professor A can proceed while contacting the instructional designer with questions as they occur. If Professor A is very experienced in online learning, pedagogy and instructional design, a meeting may not be necessary. Professor A may be able to proceed with the creation of course material and can ask questions as needed. If Professor A is a novice, then the instructional design department can try to coordinate schedules with the dean to get Professor A the course release in the spring rather than fall semester. If changing the course release time is not an option, Professor A and the instructional designer may decide to set a few brief status meetings with Professor A to address questions. In addition, Professor A would be able to email the instructional designer with questions as needed. If time permitted, the instructional designer may be able to preliminarily review Professor A's course map and material. Scenarios similar to this occur all the time in the collaborative creation of online courses. If the instructional designer refuses to budge and accommodate Professor A's and the academic department's needs, conflict is likely to result.

Tantivivat and Allen (2006) noted collaboratively developing online education can be challenging even with an instructional designer to assist in the process. Both faculty and instructional designers can work through the process in a way that can capitalize both of their strengths. However, when this does not occur and roles are not clearly delineated, duplication of effort and conflict can occur. Miller and Stein (2016) frankly discuss challenges and conflicts from the instructor designer perspective. They note faculty consider themselves the only expert even though they do not have any experience or education in teaching or learning. They note faculty believe their discipline expertise "supersedes and instructional designer's knowledge of good instructional design" (p. 1). In other words, faculty believe they know how to teach because they have been doing it for so long. However, in general, faculty are not knowledgeable about quality practices in instructional design such as the Quality Matters Rubric and accessibility standards. Miller and Stein also note conflict occurs because some faculty are very resistant to teaching differently from the way they have done in the past. This can be due to a lack of pedagogical knowledge or a lack of knowledge on how to use instructional technologies that are used in online education. In addition, faculty often view quality standards as an "impingement" on academic freedom (Miller \& Stein, 2016, p. 2).

Castro-Figueroa (2009) noted faculty are not used to interacting with professionals who are not other faculty on instructional matters. Instructional designers serve in a solitary position and "prefer to fulfill the roles of both subject matter expert and designer.... the designer may overlook the critical importance of the subject matter expert" (Castro-Figueroa, 2009, p. 24). She goes on to note content issues are the "primary combat zone for interpersonal conflicts" (p. 32). Relational issues or personality clashes are another cause and power struggles can occur when the instructional designer and faculty members need for control is equal.

Wedman (1989) clearly noted when the instructional design process is approached using designated process, procedures and strategies, resistance and conflict is less likely to occur. These processes and procedures need to be established by the instructional design department, since instructional designers usually serve as project managers, 
and coordinate with academic departments and the registrar to ensure both faculty and instructional designers have sufficient time to collaborate to effectively develop online courses with a minimum of conflict.

Campbell et al. (2009), in a study of instructional designer practices in Canada, reported the instructional designers in their study noted how important it is to build trust with faculty members. One participant in this study noted conflict is often there even before the creation of the course begins. The faculty member is passionate about the content and instructional designers are passionate about design. Merging these passions into a good working relationship requires trust, communication and explanation. Campbell et al. noted novice faculty may not be confident about teaching online or their technology skills. This creates vulnerability. If a designer is perceived as rude, demanding or too prescriptive, conflict will occur. Instructional designers who are not relational may be perceived as very difficult to work with. Faculty will likely either resist, or ask to be assigned to a different designer to complete the course.

As noted by Campbell et al. (2009), instructional designers act as advisors to faculty. They suggest what is likely to work, particularly online. However, if disagreement between the instructional designer and the faculty member occur, there needs to be policies and procedures prior to any potential conflict to ensure matters such as this can be quickly resolved. In most universities if it is a design decision, then the director of the instructional design department likely will have the final say. An example of this is a faculty member who refuses to include peer-to-peer engagement assignments, such as discussions in an online course, when this is considered a best practice.

Pan and Thompsen (2009) noted the instructional designers they interviewed indicated ultimately the final decision was the faculty members to accept or not accept instructional designers' guidance. In most universities if it is a content decision, then it is the purview of the department chair or dean. An example of this is the type of content that is to be covered and assessed. An instructional designer can suggest type of assessments that might be more optimal based on the taxonomy level designated in the course objectives. Yet, an instructional designer should never change or remove content from a course without faculty member acquiescence. In doing so, an instructional designer clearly steps outside of the boundary of instructional design and acts as a subject matter expert in a content area he/she likely has no expertise in.

Regional accrediting bodies are very specific about the education, experience and expertise a faculty member has to have to teach in a specific discipline. If instructional designers impact content and do not hold credentials in that specific discipline, these standards essentially are violated. Campbell et al. note instructional designers are required to practice outside their "zone... and are asked to deliver products they do not believe in or are assigned projects that challenge their identities" (2009.p. 661). This occurs because of the advisor role instructional designers fulfill. Instructional designers who try to control things outside their purview will cause conflict with academic leadership eventually. The creation of an online course should never be viewed as a power struggle, although sometimes it is by either the faculty member or the instructional designer. University policies need to clearly delineate what power each of these roles yield in order for collaboration to be effective.

In some universities, faculty satisfaction plays heavily into instructional designers' annual evaluations. Since instructional designers deal so closely with faculty, measuring the satisfaction of faculty is an important way to assess performance. If the collaboration is not effective, this may ultimately impact the designer's evaluation (Pan \& Thompsen, 2009).

\section{Potential Solutions}

Chao et al. (2010) noted instructional designers and faculty tend to concentrate on different quality standards when these are implemented in the course development process. Because of the differences in focus, instructional designers and faculty need to become familiar with each other's working styles. Instead of causing conflict, these different views can actually result in a better course that is content-rich and well-designed.

Perhaps the best way to decrease conflict in the course creation process is to have specific written policies and guidance. The policies can be used to delineate the roles of the instructional designer and the faculty member in the course creation process so there is no confusion. This delineation of roles can also be addressed in the written contract given to the faculty member so there is not confusion.

In addition, a course writing guide can be created to provide more detail about the course creation process for faculty. This guide can clearly establish what faculty have to provide and how it must be provided to the instructional designer. The information that can be included for faculty may include the following:

- Information on the curriculum mapping process and how it works 
- How to correctly write course objectives (also called student learning outcomes or course competencies), including the taxonomic levels that are appropriate at different levels of education

- Guidance on taxonomic match of assessments to course objectives

- Guidance on the use of technology such as video and the types of files that must be created

- Information on online pedagogies

- Information on best practices in online learning

In addition, when the instructional designer reaches out to a faculty member about a course they will be working on together, the message should be warm, cordial and outline the expectations for any formal meetings. This message should include the designer's telephone number. In addition, a sentence encouraging the faculty member to contact the designer can be helpful. This initial message, if worded properly, can begin to create a positive collegial relationship. If the message is demanding or prescriptive, this can result in a negative relationship which will make the course creation process much more difficult.

An initial meeting, either on the telephone or through an online meeting program, is crucial for faculty members who have not collaborated on courses before, or those who have had difficulty, to clearly establish the roles of the designer and faculty member. In addition, this is a good time to reinforce the deadline for the course and any late penalties if these are included on the contract. This meeting can be more productive if it is scheduled after course writing guides and other documents are sent to the faculty member so the faculty member can ask questions after reviewing the material. Meetings with experienced faculty who have collaborated on courses may not be required; email may suffice for questions and information.

Another practice which can alleviate potential conflict for instructional designers and faculty is a robust process for projecting upcoming course creation or revision needs. If these course projections are submitted to the instructional design department well in advance of when a course is needed, this ensures the faculty member has enough time to create robust curriculum and assessments. This also allows the instructional designer sufficient time to coordinate with a faculty member and assist him her to facilitate a continuing positive relationship. It also provides the instructional design department sufficient time to review course material, return it for corrections (if required), get all required approvals and build the course in the learning management system.

It is crucial for a faculty member to meet established deadlines in order for the course creation process to work smoothly and efficiently. Faculty members who miss deadlines put undue pressure on the instructional designers who are working to get courses created in time for the semester in which they are needed. When multiple faculty submit late courses, it is impossible for an instructional design department to function efficiently; it is either feast or famine. This can negatively impact the faculty member's reputation with the instructional design department.

There will always be the rare occasion where personality conflicts will interfere in the faculty member/instructional designer relationship. It is human nature. When this occurs, a different instructional designer can be assigned if there is another one available. If another designer is not available, a third party may be able to help the faculty member and designer work through their differences.

One way for the director of an instructional design department to assess his/her designers working relationship with faculty is to distribute a customer satisfaction survey to the faculty who have worked with the department in creating courses over the previous six months or one year. This can help the director assess if there is a process breakdown or if one of the designers is stepping outside of his/her role in the collaboration process. This can also identify human resource issues such as rude behavior in instructional designers so it can be dealt with. When faculty become problematic due to late course submissions or a negative/disrespectful demeanor, their deans or program chairs should be notified to take corrective action.

\section{Conclusions}

Collaboration between two different people with different professional skills and focus (such as an instructional designer and a faculty member) can be very beneficial in some instances and challenging in others. The roles of the designer and the faculty member need to be clearly delineated in writing to attempt to preclude any problems in the future. This collaborative relationship can be collegial if the faculty member and designer work together. Instructional designers must be careful not to overstep their roles and act like subject matter experts. Faculty need to not push off aspects of the course development to the instructional designer that he/she would not normally do. Both designers and faculty need to learn to respect the expertise that each brings to this collaborative role to ensure the creation of quality courses that enhance student learning. 


\section{References}

Bichelmeyer, B.A., Misanchuk, M., \& Malopinsky, L. (2001). Adapting a Master's degree course to the web: A case analysis. The Quarterly Review of Distance Education, 2(1), 49-58. ISSN 1528-3518

Campbell, K., Schwier, R. \& Kenny, R. F. (2009). The critical, relational practice of instructional design in higher education: An emerging model of change agency. Education Technology Research Development, 57, 645-663. https://doi.org/10.1007/s11423-007-9061-6

Carnevale, D. (2000, August 4). Turning traditional courses into distance education. Chronicle of Higher Education, 46(48), A37-A38.

Castro-Figueroa, A. (2009). Conflicts and communication: Instructional designer and subject matter experts developing interdisciplinary health care content. Proquest PQDT Open: Dissertation 3380482. Retrieved from http://pqdtopen.proquest.com/doc/305159744.html?FMT=ABS

Chao, I. T., Saj, T., \& Hamilton, D. (2010). Using collaborative course development to achieve online course quality standards. The International Review of Research in Open and Distributed Learning, 11(3), 106-126. https://doi.org/10.19173/irrodl.v11i3.912

Costly, J. \& Lange, C. (2016). The effects of instructor control of online learning environments on satisfaction and perceived learning. The Electronic Journal of e-Learning, 14(3), 169-180.

Cox, S., \& Osguthorpe, R.T. (2003, May / June). How do instructional design professionals spend their time? TechTrends, 47(3), 45-47, 29. https://doi.org/10.1007/bf02763476

Diamond, R. M. (2011). Designing and assessing courses and curricula: A practical guide. John Wiley \& Sons.

Fredericksen, E., Pickett, A., Shea, P., Pelz, W., \& Swan, K. (2000). Factors influencing faculty satisfaction with asynchronous teaching and learning in the SUNY Learning Network. The Journal of Asynchronous Learning Networks, 4(3). Retrieved from http://www.sloan-c.org/publications/jalnv4n3/v4n3_fredericksen.asp

Guernsey, L. (1998, December 11). A new career track combines teaching and academic computing. The Chronicle of Higher Education, pp. A35-A37.

Intentional Futures. (2016, April). Instructional design in higher education. Retrieved from http://intentionalfutures.com/reports/ instructional__design/files/Instructional\%20Design\%20in\%20Higher\% 20Education\%20Report.pdf

International Board of Standards for Training, Performance and Instruction. (2003). Instructor competencies. Retrieved from http://ibstpi.org/instructor-competencies/

International Board of Standards for Training, Performance and Instruction. (2003). Instructional designer competencies. Retrieved from http://ibstpi.org/instructional-design-competencies/

Kenney, R.R., Zhang, Z., Schwier, R. A. \& Campbell, K. (2005). A review of what instructional designers do: Questions answered and questions not asked. Canadian Journal of Learning and Technology, 31(1). https://doi.org/10.21432/t2jw2p

Luck, A. (2001, January-February). Developing courses for online delivery: One strategy. The Technology Source. Retrieved from http://technologysource.org/article/developing_courses_for_online_delivery/

Malamed, C. (2009). 10 qualities of the ideal instructional design. The Learning Coach. Retrieved from http://theelearningcoach.com/elearning_design/ 10-qualities-of-the-ideal-instructional-designer/

McGuire, R. (2016, May 5). What is an instructional designer? A comprehensive new survey of the field attempts an answer. Acrobatique. Retrieved from http://acrobatiq.com/what-is-an-instructional-designer/

Miller, S. \& Stein. G. (2016, February). Finding our voice: Instructional designers in higher education. Educause Review.

Retrieved

from http://er.educause.edu/articles/2016/2/finding-our-voice-instructional-designers-in-higher-education

Moallem, M. (2003). An interactive online course: A collaborative design model. Educational Technology Research and Development, 51(4), 85-103. https://doi.org/10.1007/BF02504545

Pan, C., \& Thompson, K., (2009). Exploring dynamics between instructional designers and higher education faculty: An ethnographic case study. Journal of Educational Technology Development and Exchange, 2(1), 33-52. https://doi.org/10.18785/jetde.0201.03 
Puzziferro, M \& Shelton, K. (2014). A model for developing high quality online courses: Integrating a systems approach with learning theory. Journal of Asynchronous Learning Networks, 12, 3-4. https://doi.org/10.24059olj.v12i3.58

Reeves, T. C., Herrington, J., \& Oliver, R. (2004). A development research agenda for online collaborative learning. Educational Technology Research and Development, 52(4), 53-65. https://doi.org/10.1007/bf02504718

Reiser, R.A. (2001). A history of instructional design and technology: Part II: A history of instructional design. Educational Technology Research and Development, 49(2), 57-67. https://doi.org/10.1007/bf02504928

Richey, R., Fields, D.C., \& Foxon, M. (2001). Instructional design competencies: The standards ( $3^{\text {rd }}$ ed.). Washington, D. C.: Office of Educational Research and Improvement. Retrieved from http://eric.ed.gov/?id=ED453803. ISBN-0-937597-52-X

Roberts, D. W., Jackson, K., Osborne, J., \& Vine, A. S. (1994). Attitudes and perceptions of academic authors to the preparation of distance education materials at the University of Tasmania. Distance Education, 15(1), 70-93. https://doi.org/10.1080/0158791940150106

Smaldino, S.E. \& Yamagata-Lynch, L. (2015). The course-in-a-box: Design issues. TechTrends, 59(4), 71-78. https://doi.org/10.1007/s11528-015-0873-7

Tantvivat, E.M. \& Allen, S. D. (2006). Instructional designers and faculty working together to create learning objects. $20^{\text {th }}$ Annual Conference on Distance Teaching and Learning Conference, University of Wisconsin.

Tracey, M. W., Hutchinson, A., \& Grzebyk, T. Q. (2014). Instructional designers as reflective practitioners: Developing professional identity through reflection. Educational Technology Research \& Development, 62(3), 315-334. https://doi.org/10.1007/s11423-014-9334-9. https://doi.org/10.1007/s11423-014-9334-9

Voogt, J., Laferrière, T., Breuleux, A., Itow, R. C., Hickey, D. T., \& McKenney, S. (2015). Collaborative design as a form of professional development. Instructional Science, 43(2), 259-282. https://doi.org/10.1007/ s11251-014-9340-7

University of Regina. (2016). Roles and responsibilities in course development. Retrieved from http://www.uregina.ca/cce/assets/docs/pdf/ distance-online/faculty-support/roles-course-development.pdf

Wedman, J.F. (1989). Overcoming resistance to formal instructional development processes. Educational Technology Research and Development, 37(4), 41-46. https://doi.org/10.1007/bf02307720

$\mathrm{Xu}, \mathrm{X} . \&$ Morris, L. V. (2007). Collaborative course development for online courses. Innovation in Higher Education, 32, 35-47. https://doi.org/10.1007/s10755-006-9033-5 